\title{
Artigo Técnico \\ MÉTOdO RESPIROMÉTRICO PARA O MONITORAMENTO DE PROCESSOS BIOLÓGICOS
}

\section{RESPIROMETRIC METHOD FOR THE MONITORING OF BIOLOGICAL PROCESSES}

\section{GIANNI ANDREOTTOLA}

Graduado em Engenharia Sanitária (1985); Doutorado em Engenharia Sanitária (1989) pelo Instituto pelo Ambiente de Milão e Pós Doutorado em Engenharia Sanitária (1991) no Departamento de Engenharia Ambiental da Universidade Técnica de Milão. Consultor da WHO (World Health Organization) e coopera com a UNEP (United Nations Environment Programme) na remediação de solos. Professor no Departamento de Engenharia Civil e Ambiental da Universidade de Trento - Trento/Itália.

\section{EDUARDO LUIZ DE OLIVEIRA}

Graduado em Engenharia Civil pela Faculdade de Engenharia de Baurú (1978), Especialização em Hidráulica e Saneamento pela USP, São Carlos (1982) e em Engenharia Sanitária (1984) pela USP São Paulo; Mestrado e Doutorado em Irrigação e Drenagem pela UNESP Botucatu (1993 e 1997); Pós-Doutorado em Engenharia Ambiental pela Universidade de Trento - Trento/Itália

(2003). Professor no Dep. de Engenharia Civil da Faculdade de Engenharia de Bauru - UNESP.

\section{PAOLA FOLADORI}

Doutora em Engenharia Sanitária pelo Politécnico de Milão, Pós-doutoranda do Departamento de Engenharia Civil e Ambiental da Universidade de Trento - Trento/Itália.

\section{LORIS DALLAGO}

Doutor em Engenharia Ambiental pela Faculdade de Engenharia da Universidade de Trento; Pós doutorando na Faculdade de Trento-Trento/Itália.

\section{Roberto PETERLINI}

Licenciando do Curso de Engenharia Ambiental da Universidade de Trento - Trento/Itália.

\section{MARIA CADONNA}

Laureada em Ciências Biológicas; responsável técnico pelo Laboratorio Chimico e Biológico do Servizio Opere Igienico Sanitarie - Trento/Itália

\section{RESUMO}

Este trabalho apresenta os atuais métodos respirométricos voltados ao controle biológico em geral, com técnicas desenvolvidas para a aplicação em tratamentos de águas residuárias, principalmente no controle de processos por lodos ativados e recentes desenvolvimentos do método para a aplicação em sistemas de tratamento por fitodepuração (Wetlands). Descreve novos métodos que foram desenvolvidos no Laboratorio di Ingegneria Sanitaria-Ambientale (LISA) da Università di Trento, Itália. Estes métodos baseiam-se em duas metodologias de laboratório para a aplicação da respirometria em fitoderuração: o primeiro caracteriza a atividade bacteriológica do solo com a finalidade de medir a concentração de $\mathrm{O}_{2}$ na fase gasosa, o outro avalia a concentração de $\mathrm{O}_{2}$ na fase aquosa.

PALAVRAS-CHAVE: Respirometria, fitodepuração, lodos ativados, processo biológico.

\begin{abstract}
This paper presents current respirometric methods for general biological control using techniques developed for application in wastewater treatment, particularly for the control of the activated sludge process. It also presents recent developments of this method for application in treatment systems of Constructed Wetlands. New methods developed in the Engineering Laboratory (Lisa) at the University of Trento (Italy) are described. The methods use two distinct lab methodologies for respirometry application in Constructed Wetlands. The first one characterizes soil bacteriological activity measuring $\mathrm{O}_{2}$ concentration in the gaseous phase and the other one measures $\mathrm{O}_{2}$ concentration in watery phase.
\end{abstract}

KEYWORDS: Respirometry, constructed wetland, activated sludge; biologicalprocesses. 


\section{INTRODUÇÃO}

Nas estações de tratamento de esgoto baseadas nos sistemas de lodos ativados, faz-se cada vez mais uso de métodos respirométricos para a determinação das características de biodegradabilidade dos afluentes e da atividade biológica do sistema. Para a aplicação de tal técnica nos sistemas a lodos ativados, existe de fato uma ampla literatura técnico-científica (Andreottola et al., 2002). No entanto, a aplicação de tal técnica a tratamentos naturais de águas residuárias (fitodepuração) apresenta-se, atualmente, numa fase de poucas experiências aplicativas e de protocolos experimentais.

No presente trabalho, se deseja ilustrar as técnicas já consolidadas para avaliar as características de biodegrabilidade das águas que ingressam a um tratamento biológico, bem como os instrumentos e os métodos inovadores de análise respirométrica de terrenos e de outras matrizes desenvolvidas no Laboratorio di Ingegneria Sanitaria-Ambientale (LISA) da Università di Trento. Os métodos apresentados estão, atualmente, em fase de validação experimental em sistemas de fitodepuraçôes de leitos horizontal e vertical, para chegar a proposição de um robusto e acurado protocolo experimental.

Foram ilustrados os métodos respirométricos de caracterização de águas residuárias, os métodos de laboratório para avaliar a atividade de uma amostra coletada de um sistema de fitodepuração e um método para a análise respirométrica "in situ".

\section{METODOLOGIA}

\section{Princípio do método para determinação da TCO (Taxa de consumo de oxigênio)}

Os primeiros a se ocuparem da técnica respirométrica foram Jenkins (1960) e Montgomery (1967), tendo como base seus próprios estudos experimentais sobre a quantificação do consumo de oxigênio dissolvido em sistemas de lodos ativados. O procedimento para estimarse a TCO é de extrema simplicidade e o campo de aplicação vastíssimo. Não obstante seja uma metodologia utilizável em grande escala, não se conseguiu uma larga difusão desta nas operações de gestão das estações de tratamento de esgoto.

O teste de TCO considera as variações na taxa de respiração do lodo em conseqüência do tipo de substrato acres- centado e da velocidade de degradação de parte da biomassa.

A absorção do oxigênio se desenvolve através de duas fases principais:

1) respiração endógena do lodo: é o oxigênio necessário para a respiração do lodo ativado, ou seja, a energia requerida para manter as funçóes das células; realiza-se a fase endógena da taxa de absorção de oxigênio;

2) degradação do substrato: representa o consumo de oxigênio por parte dos microrganismos para a degradação dos substratos presentes no líquido alimentado; neste caso se realiza a fase exógena da taxa de absorção de oxigênio e se distingue como: (2a) substratos rapidamente biodegradáveis, com uma elevada velocidade de consumo de oxigênio; (2b) substratos lentamente biodegradáveis, com velocidade de utilização do oxigênio inferior àquela precedente, porém, superior àquela endógena.

Em condições endógenas a respiração do lodo comporta uma contínua utilização do oxigênio a uma velocidade aproximadamente constante e de modesta relevância: isto é demonstrado pela inclinação uniforme da reta $a-b-c$, vista na Figura 1.

Acrescentando-se no instante $b$ uma pequena quantidade de substrato (solúvel), isento de substâncias tóxicas para os organismos presentes, provoca-se um momentâneo incremento na velocidade de absorção do oxigênio, representado pela distância $b-d$. Somente quando o substrato foi totalmente degradado, a situação no interior do sistema retorna às condiçôes endógenas iniciais, assumindo após o ponto $d$, uma inclinação similar àquela original (distância $d-e$ ).
No instante $d$, o valor da concentração de oxigênio presenteéinferioràquela que seria encontrada sem o acréscimo do substrato. A diferença, isto é, a distância $d-f$, representa a demanda de oxigênio em um breve tempo devidoà introdução do substrato.

Segundo os tipos de compostos preponderantes nas águas residuárias, adicionados ao reator de lodos, obtém-se diversos andamentos da curva de respiração. A Figura 2 apresenta três diferentes possibilidades de curvas:

$A$ - é o caso mais simples. Representa uma intensa queda na taxa de respiração, coincidindo com a adição do substrato puro, rapidamente biodegradável (por exemplo, ácido acético), seguido de um rápido retorno à inclinação da fase endógena inicial.

$B$-representa a combinação de mais substratos. Com a adição destes, a velocidade de respiração cresce fortemente mantendo valores uniformes no primeiro momento, para depois assumirem valores gradualmente mais modestos, antes de retornar à inclinação anterior.

$C$ - se observa frequentemente na presença de substâncias complexas. Inicia com um forte decréscimo, ao qual se sucede uma variação gradual para valores mais baixos da velocidade de respiração. No trecho final, atinge uma inclinação constante; porém, nestes casos dificilmente restaura a inclinação endógena inicial. $\hat{E}$ este o caso das águas residuárias municipais, nas quais há presença de mais substâncias; algumas rapidamente biodegradáveis e outras lentamente biodegradáveis, que não podem ser completamente biodegradadas durante a breve duração

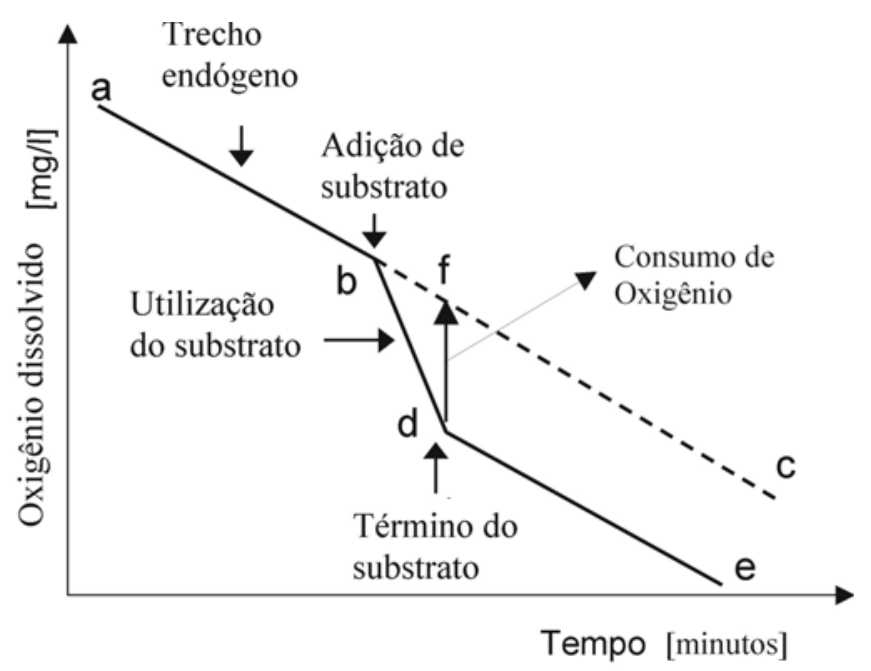

Figura I- Efeito sobre a concentração de oxigênio dissolvido, após adição ao lodo ativado de uma limitada quantidade de substrato (Andreottola et al, 2002) 


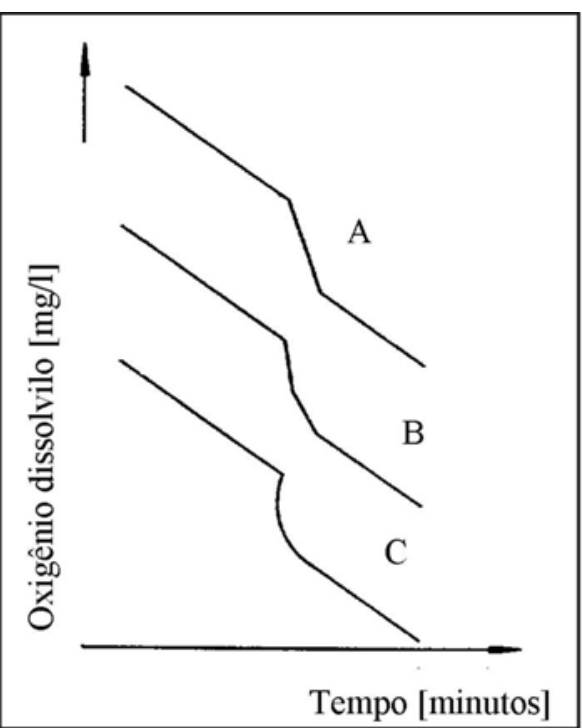

Figura 2 - Tipologia de curvas de respiração comumente observada (Andreottola et al, 2002)

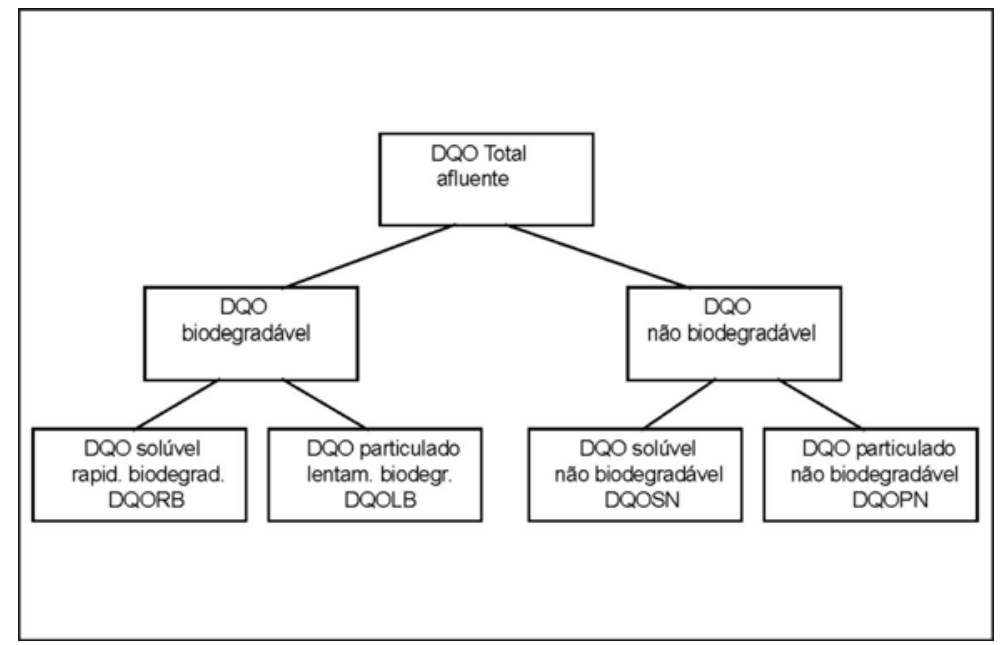

Figura 3 - Subdivisão do DQO afluente (Ekama et al, I 986 modificado) do teste; estas são responsáveis pelo fato da inclinação do trecho final ser maior que a inclinação endógena inicial.

\section{O teste de TCO para a caracterização dos substratos orgânicos}

Se por um lado os parâmetros de TCO e TCO específico, de fácil determinação experimental, permitem obter importantes indicaçóes sobre a caracterização da biomassa, fornecendo informaçôes sobre a atividade dos organismos heterótrofos e autótrofos em função de substratos potencialmente inibidores, por outro lado, tais testes podem ser aplicados para a quantificação do substrato orgânico presente em uma água residuária afluente.

Para a determinação das características da água residuária, utiliza-se a subdivisão da DQO no afluente em frações que sejam associáveis a um certo comportamento típico durante o processo de degradação. Uma subdivisão da DQO afluente é aquela apresentada por Ekama et al (1986) e mostrada na Figura 3: a DQO que ingressa é separada em uma fração biodegradável e em uma não biodegradável, cada uma das quais é subdividida, em duas frações: solúvel e particulada. Na porção biodegradável, a fração solúvel coincide com o substrato rapidamente biodegradado, enquanto a fração particulada é associada ao substrato lentamente biodegradável. A classificação da DQO, portanto, se baseia não só sobre uma distinção física, mas sobretudo em um comportamento biológico diferente.

\section{Método direto para a determinação da DQO rapidamente biodegradável (DQORB)}

A hipótese fundamental sobre a qual se baseia o método proposto para a determinação da DQORB é que a biomassa assimila a fração rapidamente biodegradável da DQO do mesmo modo que assimila o acido acético ou o acetato de sódio. Este método permite a determinação da concentração de DQORB mediante um teste chamado a simples-TCO, uma vez que é suficiente dispor de um único trecho decrescente da concentração de OD.

A DQORB é calculada a partir do OD consumido com base em uma curva de calibração_obtida mediante a aplicação de acetato de sódio (ácido acético), segundo o procedimento formulado originalmente por Xu e Hultman (1996) e retomado, sucessivamente, por Ziglio et al (2001). Como alternativa a este método, uma outra metodologia foi proposta na literatura; no entanto, esta é baseado na interpretação do respirograma inteiro (por isso são indicados como multi-TCO), porém, requerer 2-3 horas para ser realizada (Ekama et al, 1986; Kappeler e Gujer, 1992).

A vantagem do método simples-TCO consiste no breve tempo requerido para a execução, próximo a 30 minutos. A equi- valência entre os resultados fornecidos pelos dois tipos de teste foi verificada por Ziglio et al (2001).

\section{A curva de calibração entre OD e DQORB}

No método simples-TCO assume-se que a biomassa utiliza a DQORB presente na água residuária, do mesmo modo que utiliza o acetato de sódio $\left(\mathrm{CH}_{3} \mathrm{COONa}\right)$. Para a quantificação da DQORB é necessário dispor de uma curva de calibração que exprima: a correlação entre a DQO adicionada (como acetato de sódio) e o consumo relativo de oxigênio da parte do líquido. Para calcular a curva de calibração entre OD utilizado e DQO consumida é necessário dispor de 5-6 pontos (Figura 4); cada ponto é obtido com uma dosagem diferente de acetato.

\section{Determinação da DQORB na água resỉduária}

Para a quantificação da DQORB de uma água residuária, se dosa, no início do teste, uma quantidade de líquido filtrado, em geral em alíquotas de $10-100 \mathrm{~mL}$ por 1 litro de líquido amostrado. $\mathrm{O}$ traçado que se obtém da aplicação deste procedimento é mostrado na Figura $5 . \mathrm{Na}$ primeira parte do traçado, a maior inclinação é relativa à oxidação da DQORB. Com relação à remoção completa da DQORB, não se observa geralmente uma 


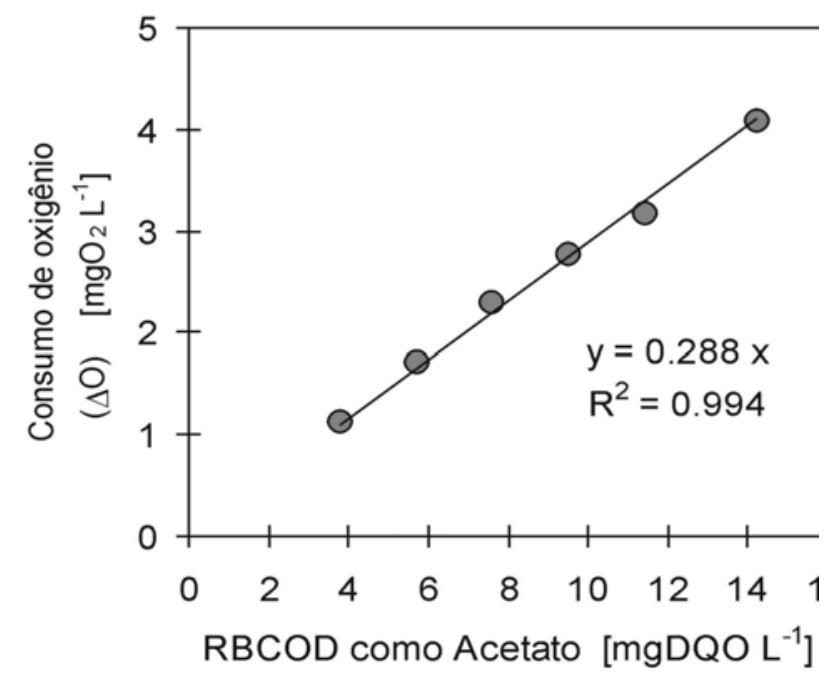

Figura 4 - Curva de calibração para converter o consumo de oxigênio ( $\triangle O D$ ) em DQORB

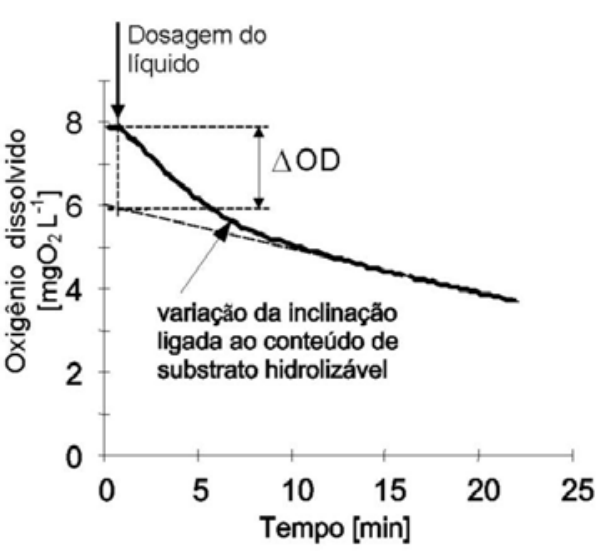

Figura 5 - Dinâmica da concentração de OD logo após a adição do líquido visível mudança de declividade (como no caso de um substrato puro como o acetato). Este comportamento é devido à presença de substratos rapidamente hidrolisáveis, cuja oxidação causa uma variação gradual na inclinação de OD. No trecho sucessivo, a inclinação menor representa a respiração endógena, anterior à adição do líquido. Interpola-se este segundo trecho e se extrapola a inclinação até o tempo $t_{0}$, correspondente a adição do substrato. Esta construção gráfica permite medir graficamente o valor do $\Delta \mathrm{OD}$ consumido durante o teste, logo após a adição do substrato.

\section{Quantificação da DQO biodegradável total}

Mediante a aplicação de uma série seqüencial de testes de TCO, é possível extrair um respirograma experimental, como aquele reportado na Figura 6, derivado da degradação do substrato a ser testado e da biomassa do sistema. O respirograma da Figura 6, obtido para uma água residuária municipal, apresenta um andamento gradualmente decrescente ligado à progressiva diminuição dos substratos biodegradáveis, dos mais velozes aos mais lentos. A TCO apresenta valores elevados no início do teste; nesta fase se verifica, sejam as oxidaçōes da DQORB e da DQOLB (DQO Lentamente Biodegradável), seja a hidrólise da DQORH (DQO Rapidamente Hidrolisável). A duração temporal desta primeira fase, com valores elevados de TCO, depende da quantidade de

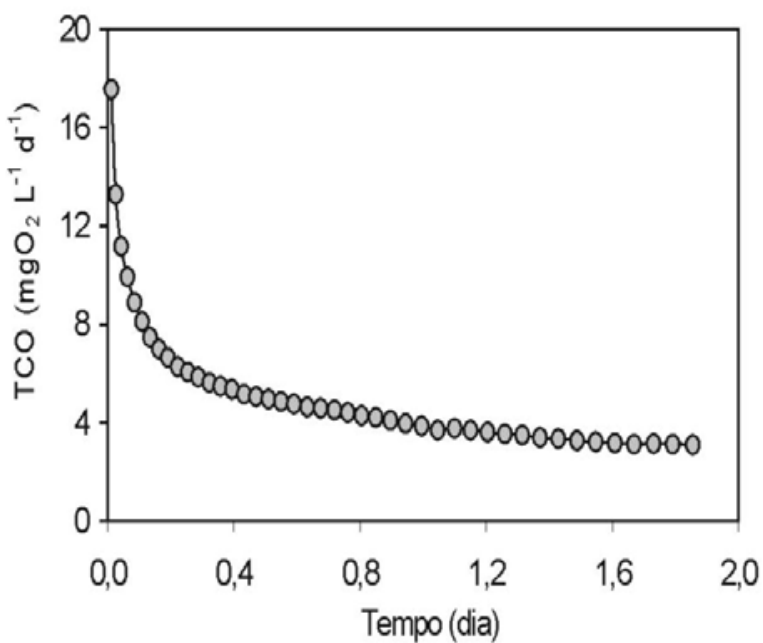

Figura 6 - Respirograma relativo à oxidação do substrato biodegradável presente em amostra de lodos ativados de um tratamento de água residuária municipal

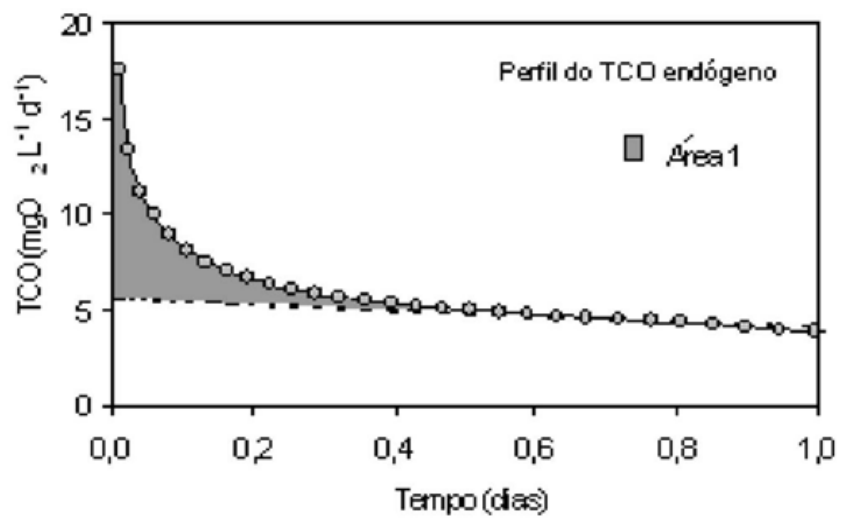

Figura 7- Respirograma relativo à oxidação do substrato biodegradável de uma água residuária municipal com indicação da curva de decaimento endógeno 
DQORB efetivamente disponível na amostra alimentada.

A parte final do respirograma corresponde à respiração endógena. Este trecho deve ter um comprimento suficiente para ser interpolado com uma função exponencial prolongável até o tempo inicial. A área compreendida entre o respirograma total e a respiração endógena (área 1 da Figura 7) individualiza o oxigênio total (DOD) utilizado para a oxidação de toda a DQO biodegradável $\left(\mathrm{DQO}_{\mathrm{b}}\right)$ na água residuária, constituído das fraçōes rapidamente biodegradáveis, rapidamente hidrolisáveis e lentamente biodegradáveis.

O valor da "Área 1" é calculado como a diferença entre a integral do respirograma e a integral da curva de decréscimo endógeno e, para ambas, pode-se utilizar o método de integração dos trapézios. Sobre a base do oxigênio total consumido, calcula-se a quantidade de DQO efetivamente biodegradável, mediante a seguinte expressão:

$$
\Delta B O D_{b}=\frac{1}{1-f_{c v} \cdot Y_{H}} \cdot \Delta O D \cdot \frac{V_{l i q}+V_{f}}{V_{l i q}}
$$

Onde $\mathrm{V}_{\mathrm{f}}$ é o volume ótimo de lodo e $\mathrm{V}_{\text {liq }}$ o volume ótimo de água residuária para execução do teste (Andreottola et al, 2002), $f_{c v}$ representa o coeficiente de conversão entre DQO e SSV, igual a 1.42$1.48 \mathrm{mg} \mathrm{DQO} \mathrm{mg} \mathrm{SSV}^{-1} \mathrm{e} \mathrm{Y}_{\mathrm{H}}$ representa o coeficiente de produção celular específica das bactérias heterotróficas, igual a $0.45 \mathrm{mg} \mathrm{SSV} \mathrm{mg} \mathrm{DQO}^{-1}$.

Conhecer a concentração de DQO biodegradável total de uma água residuária, ainda que não necessariamente subdividida em suas frações DQORB, DQORH e DQOLB, constitui-se em uma útil informação para conduzir diversas averiguações funcionais na otimização de tratamentos de águas residuárias.

\section{Determinação da fração ativa heterotrófica}

A fração ativa heterotrófica em uma água residuária sem qualquer tratamento ou pré-sedimentada, pode ser determinada com um simples teste respirométrico realizado diretamente com a água residuária com prévia adição de ATU (allylthiourea), visando à inibição da nitrificação. O teste, conduzido com elevada relação $S_{0} / \mathrm{X}_{0}$, geralmente maior que 4, foi proposto por Kappeler e Gujer (1992). Este se baseia em um respirograma de crescimento exponencial da biomassa bacteriana, induzida pelo substrato rapidamente biodegradável presente na água residuária. Nos casos em que a água residuária não contenha substrato rapidamente biodegradável, suficiente para garantir o crescimento exponencial, pode-se fazer a complememtação com um substrato sintético (como o Acetato de Sódio), com o propósito de garantir uma relação $\mathrm{S}_{0} / \mathrm{X}_{0}$ ótima.

A expressão que descreve o consumo de oxigênio no tempo, em um teste sem limite de substrato, é do tipo:

$$
T C O(t)=\left(\frac{1-Y_{H}}{Y_{H}} \mu_{H, \max }-b_{H}\right) \cdot X_{H, 0} \cdot e^{\left(\mu_{H, \max }-b_{H}\right) \cdot t}
$$

Elaborando o respirograma, é possível calcular a biomassa ativa inicial $\left(\mathrm{X}_{\mathrm{H}, 0}\right)$. Além da inclinação do respirograma, diagramado em um plano $\ln$ (TCO) vs. Tempo, é possível calcular o termo $\left(\mu_{\mathrm{H}, \max }-\mathrm{b}_{\mathrm{H}}\right)$ onde $\mu_{\mathrm{H} \text {,max }}$ é a velocidade máxima específica de crescimento para bactérias heterotróficas e $b_{H}$ é o coeficiente de decaimento endógeno, que neste caso é assumido como sendo igual a $0.24 \mathrm{~d}^{-1}$. Na literatura, os valores de $b_{H}$ variam amplamente entre 0.1 e $0.4 \mathrm{~d}^{-1}$, sendo que esta variabilidade não influencia o cálculo da biomassa ativa, implicando em variações dos resultados finais na ordem de $2 \%$. Em conseqüência, não se comete grande erro se no lugar de se determinar o valor $\mathrm{de}_{\mathrm{H}} \mathrm{b}_{\mathrm{H}}$ próprio para um caso específico, se assumir um valor de literatura, entre os quais é considerado mais representativo aquele igual a $0.24 \mathrm{~d}^{-1}$ (Ekama et al, 1984).

Calcula-se a biomassa ativa partindo da expressão:

$$
X_{0}=\frac{e^{(y-\text { int erseçao })} \cdot 24}{\frac{1-Y_{H}}{Y_{H}} \cdot\left(\text { inclinação }+b_{H}\right)}
$$

Onde $\mathrm{Y}_{\mathrm{H}}$ é assumido como sendo igual a 0.67 (mg DQO mg DQO-1) utilizando-se um coeficiente de conversão entre DQO e SSV igual a $1.48 \mathrm{mg}$ DQO $\mathrm{mg} \mathrm{SSV}^{-1}$. Um exemplo de um respirograma para a determinação da biomassa ativa em um gráfico de TCOxTempo é indicado na Figura 8.

\section{Técnicas respirométricas para a caracterização de solos}

A exigência de utilização de métodos respirométricos para a investigação de processos de fitodepuração nasce da crescente exigência de se dispor de parâmetros de projeto sempre mais detalhados. Tais exigências tornar-se-ão mais importantes num futuro próximo, no momento em que se difundirão métodos avançados para o dimensionamento dos processos de fitodepuração. Em tal consideração, verifica-se que para os processos convencionais de lodos ativados são disponíveis, atualmente, modelos de simulação bastante avançados (por exemplo o ASM do IAWQ), ao passo que não são disponíveis modelos análogos para simular os tratamentos por fitodepuração. Para estes processos estão disponíveis na literatura somente alguns modelos, que envolvem os parâmetros cinéticos e estequiométricos das principais reações bacterianas, ligadas à remoção da substância orgânica e à nitrificação; porém, tratam-se, geralmente, de modelos ainda muito simplificados. Os critérios de projeto comumente utilizados para o dimensionamento de tratamento de fitodepuração são baseados em expressôes cinéticas muito simples, em geral do tipo linear. Os processos biológicos desenvolvidos nos tratamentos de fitodepuração não podem, contudo, serem sempre considerados do tipo linear, como de fato pode-se facilmente imaginar, considerando-se que os processos biológicos, em geral, são regulados pelas expressóes de Monod ou pela cinética de ordem 1 ou $1 / 2$, como por exemplo nos biofilmes. Desta complexibilidade nasce a necessidade de se dispor de testes adaptados às medidas dos parâmetros cinéticos da parte do solo que contribui nos processos de fitodepuração. Pesquisas respirométricas com solos podem representar uma promissora alternativa, fornecendo informaçôes inerentes às atividades biológicas e às velocidades em que se desenvolvem tais reaçóes.

Os testes respirométricos permitem o monitoramento a intervalos de tempo, das concentraçôes de oxigênio (no ar ou dissolvido na água) no interior do ambiente onde está presente a amostra de terreno (ar ou água); com base na variação da concentração de oxigênio, pode se calcular o valor da TCO por meio da determinação da inclinação da reta de regressão estatística entre os dados levantados, a qual é freqüentemente linear ou aproximadamente linear (Andreottola et al, 2002).

$\mathrm{O}$ andamento da TCO no decorrer do tempo pode depender de diversos fatores, tais como: temperatura, concentração de oxigênio, quantidade de substân- 


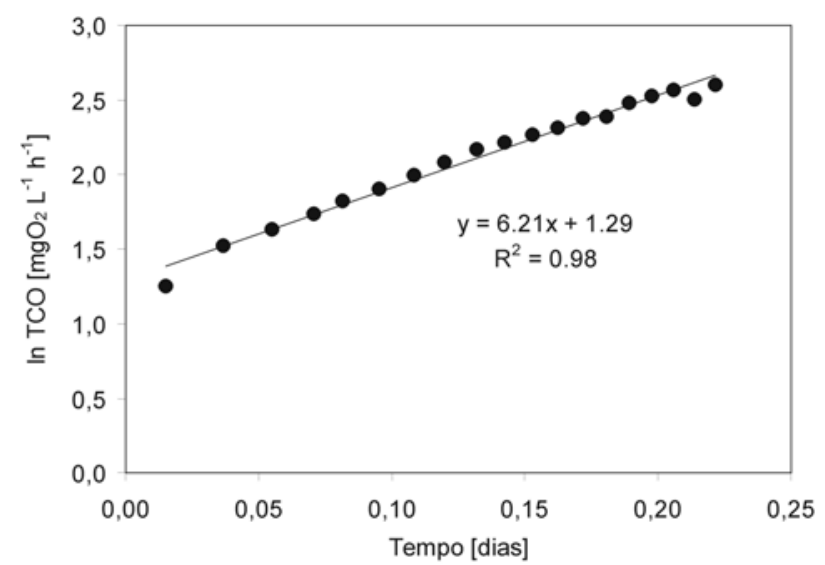

Figura 8 - Exemplo de curva respirométrica obtida para uma água residuária, após sedimentação primária (é indicado o InTCO vs. tempo)

Tabela I - Valores dos parâmetros retirados da Figura 8

\begin{tabular}{cc}
\hline & $\begin{array}{c}\text { Líquido } \\
\text { pré-sedimentado }\end{array}$ \\
\hline y-interseção $\left[\mathrm{mgO}_{2} \mathrm{~L}^{-1} \mathrm{~h}^{-1}\right]$ & 1,29 \\
inclinação TCO $\left(\mu_{\left.\mathrm{H}{ }_{\text {max }}-\mathrm{b}_{\mathrm{H}}\right)\left[\mathrm{d}^{-1}\right]}\right.$ & 6,21 \\
biomassa ativa $\left(\mathrm{X}_{0}\right)\left[\mathrm{mgDQO} \mathrm{L}^{-1}\right]$ & 27,4 \\
\hline
\end{tabular}

cia orgânica adsorvida sobre as partículas, presença de nitrogênio nitrificante, granulometria do material que influencia a superfície específica e, portanto, a atividade do leito. Os principais termos que contribuem com o valor final da TCO são os seguintes:

1) consumo endógeno de oxigênio $\left(\mathrm{TCO}_{\text {endógeno }}\right)$ : este termo se mede na ausência de substrato e está ligado à respiração celular da qual deriva a energia necessária para garantir as funções das células;

2) consumo de oxigênio para a oxidação do substrato carbônico (TCOcod): consumo de oxigênio necessário para a oxidação da fração orgânica biodegradável presente no líquido e para a síntese de novos materiais celulares;

3) consumo de oxigênio para a nitrifiçãao $\left(\mathrm{TCO}_{\text {nitrificaçăo }}\right)$ : consumo de oxigênio necessário para a oxidação dos compostos nitrogenados $\left(\mathrm{NH}_{4}, \mathrm{NO}_{2}\right)$.

A velocidade de consumo de oxigênio durante o processo de degradação dos substratos e das sínteses celulares é muito mais alta em relação àquela relativa somente à respiração. Os substratos rapidamente biodegradáveis, presentes nas águas residuárias, apresentam uma elevada demanda de oxigênio em um curto espaço de tempo. Reduzindo a concentração do substrato, a velocidade de consumo de oxigênio progressivamente di- minui, atingindo o valor da velocidade endógena depois do desaparecimento do substrato. No caso da oxidação de compostos lentamente biodegradáveis, verifica-se uma baixa velocidade do consumo de oxigênio, sendo muito próxima da velocidade de consumo endógena.

$\mathrm{Na}$ avaliação do balanço de oxigênio para um leito de fitodepuração, devese computar também fluxos de ingresso de oxigênio oriundo de fontes externas ao leito: estes são reconduzidos pelas seguintes contribuiçóes:

1) transferência de oxigênio do ar para a fase líquida: esta contribuição é maior em processos de fitodepuração a fluxos verticais não submersos, isto é, operados à percolação, quando comparados aos operados sempre submersos;

2) transferência de oxigênio do ar pelas raízes à fase líquida: esta contribuição é função das características e da distribuição das raízes das plantas; algumas experiências na literatura parecem sugerir que a contribuição de oxigênio do aparato radicular ao leito pode ser considerada sem importância;

3) oxigênio presente no afluente: se está presente em quantidade elevada, pode contribuir significativamente com a introdução de oxigênio no leito. Geralmente, no entanto, os afluentes chegam a uma estação de tratamento de fitodepuração em condições fortemente sépticas, com concentraçóes de oxigênio próximas a zero. É o caso, por exemplo, de líquidos provenientes de fossas Imhoff, nos quais o sistema de fitodepuração desenvolve um papel de pós-tratamento da substância orgânica e/ou nitrificante. Certa contribuição de oxigênio ao leito pode ser fornecida no caso em que se alimenta o sistema de fitodepuração com efluente secundário já tratado (por exemplo, derivado de um tratamento de lodos ativados); neste caso o tratamento com fitodepuração tem papel de polimento do efluente.

A medida do consumo de oxigênio no leito com fitodepuração pode ser efetuada através de respirômetros "in-situ" ou respirômetros de laboratório. No primeiro caso, o consumo de oxigênio é medido diretamente no campo; no segundo as amostras do solo (leito) são retiradas no campo e submetidas a testes respirométricos em laboratório.

As principais diferenças entre as duas metodologias de pesquisa estão ligadas ao fato de que, para os testes de laboratório se utilizam porçōes do terreno inevitavelmente remanejadas, enquanto no caso "insitu" pode-se efetuar medidas sem alterar significativamente o terreno. Além disto, no caso do teste "in-situ" pode-se avaliar também a contribuição de oxigênio introduzido pelas raízes das plantas.

O teste "in-situ" é mais prático para a medição do consumo de oxigênio em tratamentos de fitodepuração de fluxo horizontal do que de fluxo vertical. Porém, não é sempre possível utilizar tais técnicas para medir parâmetros cinéticos específicos, como por exemplo: a velocidade de remoção dos substratos carbônicos a velocidade de decaimento da biomassa bacteriana ou a velocidade de nitrificação. Esta limitação é devida ao fato que, para medir tais parâmetros cinéticos é necessário submeter o terreno a condições operativas particulares, como por exemplo, a adição de quantidades conhecidas de substratos a um determinado volume de amostra, ou ausência de carregamento de oxigênio por um tempo prolongado (por exemplo, para medir-se o decaimento celular endógeno).

Tais condiçỗes nem sempre são possíveis de serem realizadas para um tratamento de fitodepuração real, quando operado em contínuo. Para medidas de parâmetros cinéticos, os testes respirométricos de laboratório são mais flexíveis, podendose aplicar com maior facilidade as condiçôes operativas desejadas. O Laboratório di 
Ingegneria Sanitaria e Ambientale (LISA) dell'Università di Trento (Trento - Itália) vem, há tempos, realizando pesquisas para desenvolver métodos respirométricos sobre matrizes sólidas. No âmbito destas pesquisas, foi desenvolvido um respirômetro de laboratório para medir as variaçóes de oxigênio no ar.

Neste mesmo laboratório foi idealizado outro tipo de respirômetro para mediçōes do consumo de oxigênio dissolvido, a partir de uma coluna de terreno, em fase aquosa. Até o presente momento, foram testadas com este respirômetro algumas amostras de terreno na configuração de um leito de fluxo vertical. O objetivo da implementação e aplicação deste instrumento consiste em medir a velocidade de consumo de oxigênio ao longo do tempo, com o objetivo de estimar os parâmetros cinéticos relativos ao processo de remoção de substâncias orgânicas e à nitrificação.

\section{Exemplo de um método respirométrico "in-situ"}

Giraldo e Zarate (2001) propuseram uma aplicação do método "in-situ" para um tratamento com fitodepuração na Ilha de San Andrés (Colombia), fazendo parte de um tratamento de esgoto sanitário municipal, com capacidade para 550 habitantes. Neste estudo foram aplicadas técnicas respirométricas para a avaliação da atividade biológica de um sistema de fitodepuração de fluxo vertical, com um leito de altura igual a $60 \mathrm{~cm}$. Neste tratamento, a carga hidráulica projetual é igual a $6.1 \mathrm{~L} \mathrm{~m}^{-2} \mathrm{~h}^{-1}$ com uma velocidade de $0.5 \mathrm{~L} \mathrm{~s}^{-1}$ e um tempo de percolação no leito vertical de 7 minutos. Os testes respirométricos foram realizados segundo o esquema sintetizado na Figura 9.

Os testes respirométricos foram efetuados mediante coleta de ar do leito a diferentes profundidades $(20,40,60 \mathrm{~cm})$. $\mathrm{O}$ ar extraído foi enviado a um analisador de gás com infravermelho para a medição $\mathrm{de}_{2} \mathrm{e} \mathrm{CO}_{2}$. No que se refere à modalidade de execução, o leito deve repousar por um período de aproximadamente 3 dias, antes do início do teste. Deste modo, é possível medir a atividade endógena do mesmo. Após a adição do líquido, verifica-se o consumo de oxigênio empregado na remoção dos substratos, assim como o oxigênio consumido na respiração endógena. A utilização de aparelhos com leituras de parâmetros como $\mathrm{O}_{2}$ e $\mathrm{CO}_{2}$ permitiu avaliar a presença simultânea de atividades aeróbicas e anaeróbias. Para ten-

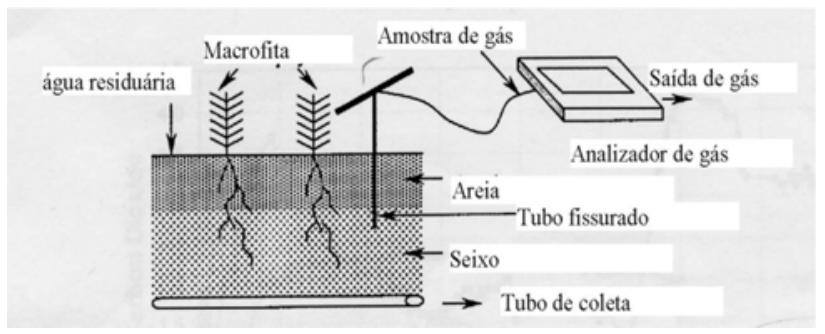

Figura 9 - Esquema do respirômetro "in-situ” para fitodepuração (realizado por Giraldo e Zarate, 200I)

tar avaliar a presença de fenômenos anaeróbios, os autores utilizaram uma sonda de $\mathrm{CH}_{4}$, a qual não registrou porcentuais significativos da presença deste gás. A pesquisa respirométrica permitiu a obtenção de importantes informações sobre o comportamento do processo em termos de oxigênio requerido e sobre a produção de gases, entre eles, o anidrido carbônico $\left(\mathrm{CO}_{2}\right)$ e o metano $\left(\mathrm{CH}_{4}\right)$. Os resultados permitiram apresentar as seguintes consideraçôes:

- há um rápido decréscimo de oxigênio na fase inicial, com uma duração de aproximadamente 20 minutos;

- o oxigênio diminui mais lentamente nos 90 minutos sucessivos;

- o conteúdo de $\mathrm{CO}_{2}$ aumenta rapidamente na fase inicial para depois diminuir, gradualmente, ao longo do tempo;

- na fase inicial, quando a demanda de oxigênio é máxima, a produção de gás metano também é maior.

\section{RESULTADO E DISCUSSÃO}

\section{Métodos respirométricos de laboratório desenvolvidos no LISA (Laboratorio di Ingegneria Sanitaria e Ambientale)}

Medida de concentração de $\mathrm{O}_{2}$ na fase gasosa

O respirômetro para a determinação doconsumo de oxigênio na fase gasosa foi inteiramente desenvolvido e construído pelo Laboratorio di Ingegneria Sanitaria e Ambientale, durante o desenvolvimento da tese de doutorado de Dallago (2002). O instrumento, denominado AIR NL (Analisador de Índice Respirométrico e Oxigênio Não Limitado), permite operar com matrizes sólidas e foi derivado do clássico respirômetro para as análises de TCO múltiplas em líquidos, isto é, a medição da velocidade de consumo do oxigênio no tempo, de uma amostra sob análise. O respirômetro, representado na Figura 10, é composto fundamentalmente de um reator com um termostato para o alojamento da amostra e de duas sondas, que medem diretamente os parâmetros: oxigênio e temperatura, sendo possível, assim, determinar o índice respirométrico com a simples verificação direta da inclinação da curva de desoxigenação.

O aparelho é constituído de um reator com termostato, conectado a dois circuitos pneumáticos. O primeiro, de alta vazão $(20 \mathrm{l} / \mathrm{min})$, permite controlar, mediante a abertura ou of fechamento de um par de eletroválvulas (que permitem ou impedem a troca de ar com o ambiente externo), o teor de oxigênio no interior do sistema. Um umidificador, instalado neste circuito, tem a função de controlar para que não diminua a umidade do material em análise.

A amostra do material (lodo, composto, terreno) é colocada em um cesto apropriado (Figura 11) com fundo perfurado, permitindo a fácil manipulação das amostras, quando necessário.

O segundo circuito é destinado para baixas vazões e serve somente como circuito de medida. Por problemas de condensação da umidade sobre a sonda de oxigênio, a este circuito integrou-se um desumidificador de sal de silício (Figura 12).

As condiçõos operativas fazem com que se tenha uma velocidade aparente de ar no estrato do material de $0,6 \mathrm{~cm} / \mathrm{s}$ e um teor mínimo de oxigênio de $18,5 \%$.

A coleta, a elaboração dos dados e o controle das eletroválvulas são realizados, totalmente, a partir de um software apropriado, denominado INNET.

Para o cálculo do índice respirométrico, parte-se da curva de concentração de oxigênio. Os trechos descendentes são identificados automaticamente e com base em um "set point" de cálculo; assim, vem calculada uma inclinação sobre uma parte da curva (Figura 13). 


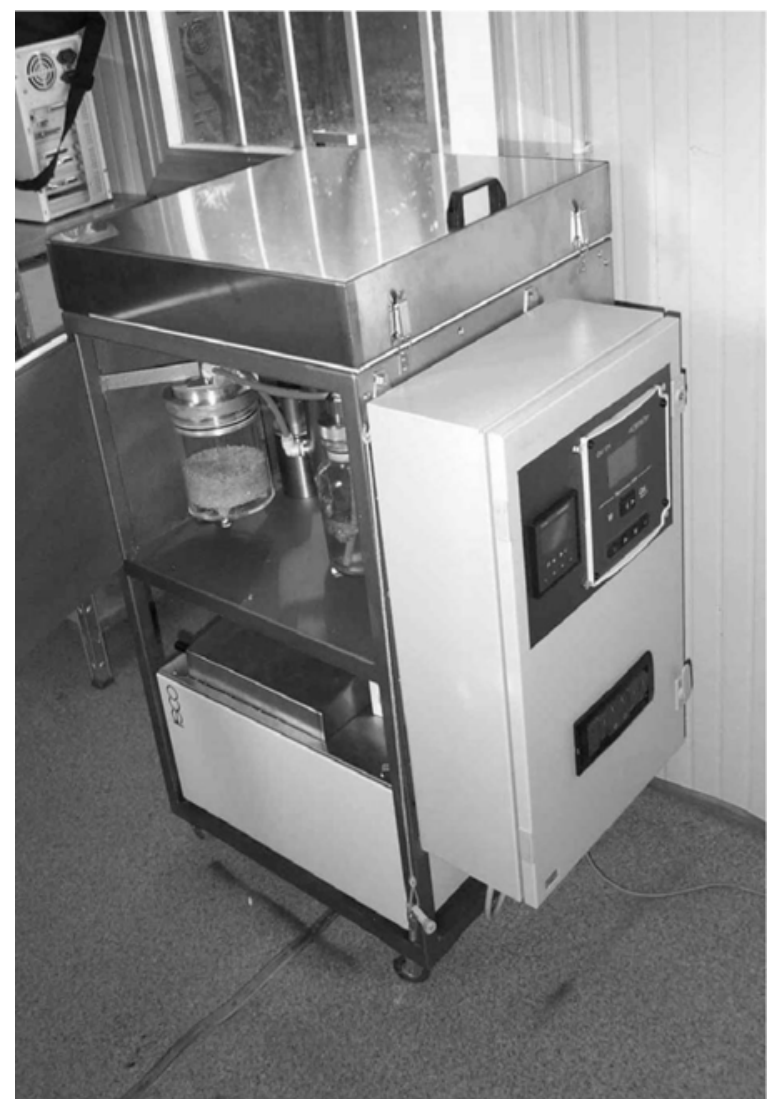

Figura 10 - Respirômetro AIR NL desenvolvido pelo LISA-Università di Trento

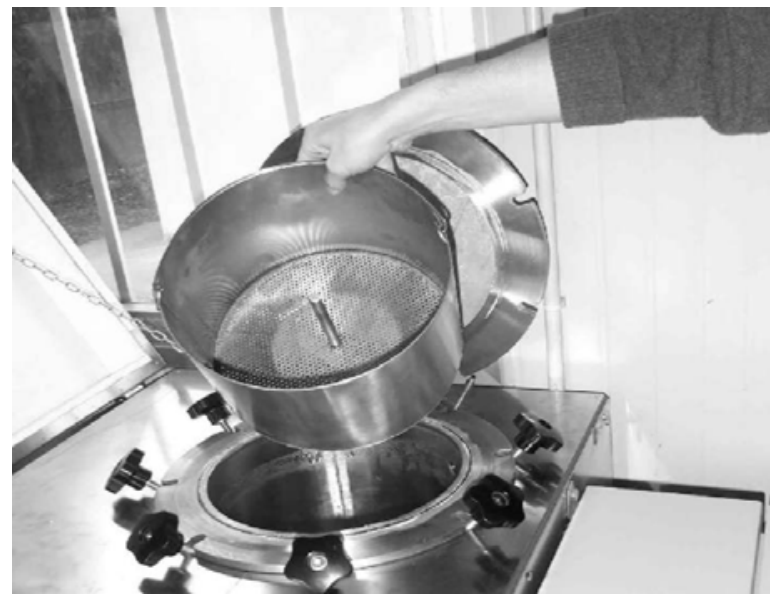

Figura I I- Cesto de alojamento do material

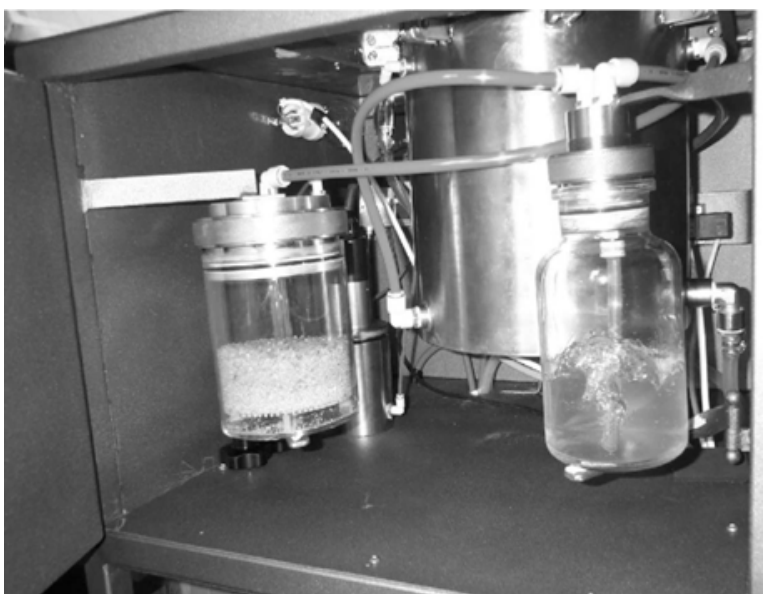

Figura I 2 - Desumidificador de sal de silício e umidificador

total de $85 \mathrm{~cm}$ (60 cm de leito filtrante). O material de enchimento, que neste caso representa um leito de fitodepuração a fluxo vertical (segundo o esquema proposto por Cooper et al, 1996), é constituído por (partindo-se de baixo para cima):

$-20 \mathrm{~cm}$ de seixo com granulometria de 30-70 mm;

$-10 \mathrm{~cm}$ de seixo com granulometria de 6-16 mm;

$-20 \mathrm{~cm}$ de areia com granulometria de 0-6 mm;

$-10 \mathrm{~cm}$ de areia com granulometria de $0-3 \mathrm{~mm}$.

Para o monitoramento contínuo do oxigênio, a coluna é equipada com os seguintes instrumentos:

a) bomba de recirculação, com fluxo da parte inferior até o alto da coluna;

b) compressor de ar para o fornecimento de oxigênio, insuflando-o na parte superior da coluna;

c) sondas para medir o oxigênio dissolvido, posicionadas: uma na parte alta e a outra na parte baixa da coluna. Os oxímetros são dotados de sistema de aqui- 
sição de dados conectado a um PC. A aquisição do sinal é automática, com freqüência entre 5 segundos a 1 minuto.

Para a execução do teste, o leito deve ser completamente preenchido com o líquido a ser tratado no sistema de fitodepuração. O teste respirométrico pode ter uma duração de várias horas. Todo o sistema foi inserido em uma incubadora para mater a temperatura controlada a $20^{\circ} \mathrm{C}$.

Um exemplo de curva obtida sobre uma porção do leito com fluxo vertical é mostrado na Figura 16, ao qual foi adicionada água residuária, após esta ter sido submetida à sedimentação primária.

Observando o comportamento do oxigênio dissolvido no exemplo da Figura 16, verifica-se que o consumo é muito rápido inicialmente, sendo que, após aproximadamente duas horas, o oxigênio é conduzido a valores inferiores a $1 \mathrm{mgO}_{2} \mathrm{~L}^{-1}$. A velocidade média de consumo do oxigênio nas primeiras 3 horas (TCO média) é igual a $1.8 \mathrm{mgO}_{2} \mathrm{~L}^{-1} \mathrm{~h}^{-1}$. Este valor se deve à presença da água na porosidade do material de enchimento (próxima a $35 \%$ ). Reportando este valor por unidade de volume de solo $\left(1 \mathrm{~m}^{3}\right)$, obtém-se um consumo de oxigênio médio de aproximadamente $500 \mathrm{mgO} \mathrm{m}^{-3} \mathrm{~h}^{-1}$. Com base neste dado, é possível prever a quantidade de substrato carbônico (em termos de $\mathrm{BOD}_{5}$ ou, melhor, de DQO biodegradável) que o leito é capaz de remover e, portanto, qual deve ser a carga orgânica a ser aplicada para um correto dimensionamento do sistema.

\section{CONCLUSÃO}

A TCO representa um dos principais componentes a ser quantificado no procedimento de projeto e/ou gestão do tratamento de águas residuárias, uma vez que este depende da quantidade de oxigênio que se tornará disponível para o processo biológico no solo. É importante conhecer se o processo de biodegradabilidade no solo se realiza em condiçōes aeróbias, apresentando assim suficiente $\mathrm{O}_{2}$ em fase aquosa, ou em condições anaeróbias, após o oxigênio ser completamente exaurido.

$\mathrm{O}$ fato do oxigênio ser consumido rapidamente sugere que, nos tratamentos reais de fitodepuração a fluxo vertical submerso, estabelecem-se períodos de anoxia com desenvolvimento de processos anaeróbicos. Na literatura, alguns autores apresentam resultados semelhantes, indicando o desenvolvimento de bactérias metanogênicas em tratamentos de tal natureza, com produção significativa de

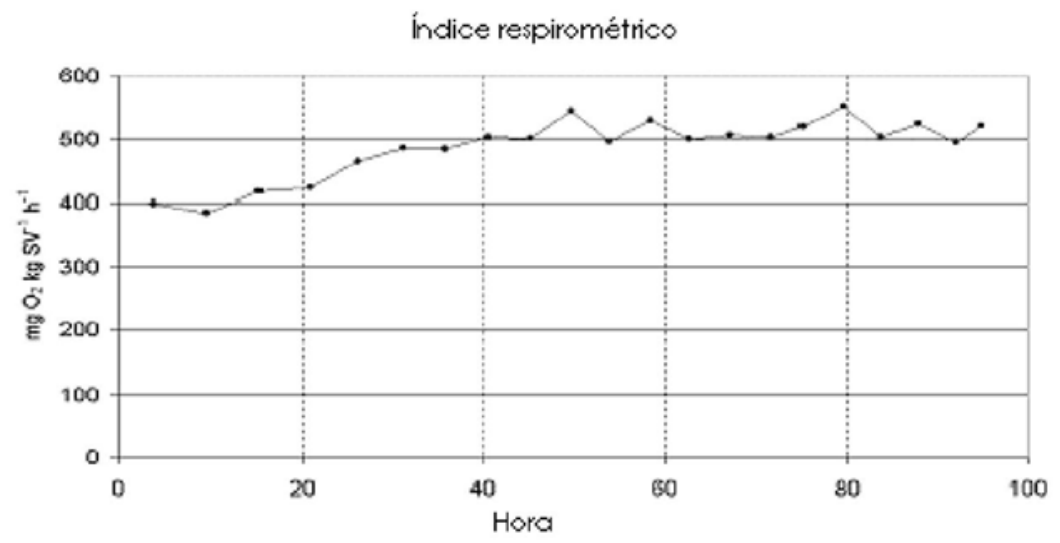

Figura I 4 - Exemplo de traçado respirométrico elaborado a partir da curva de desoxigenação

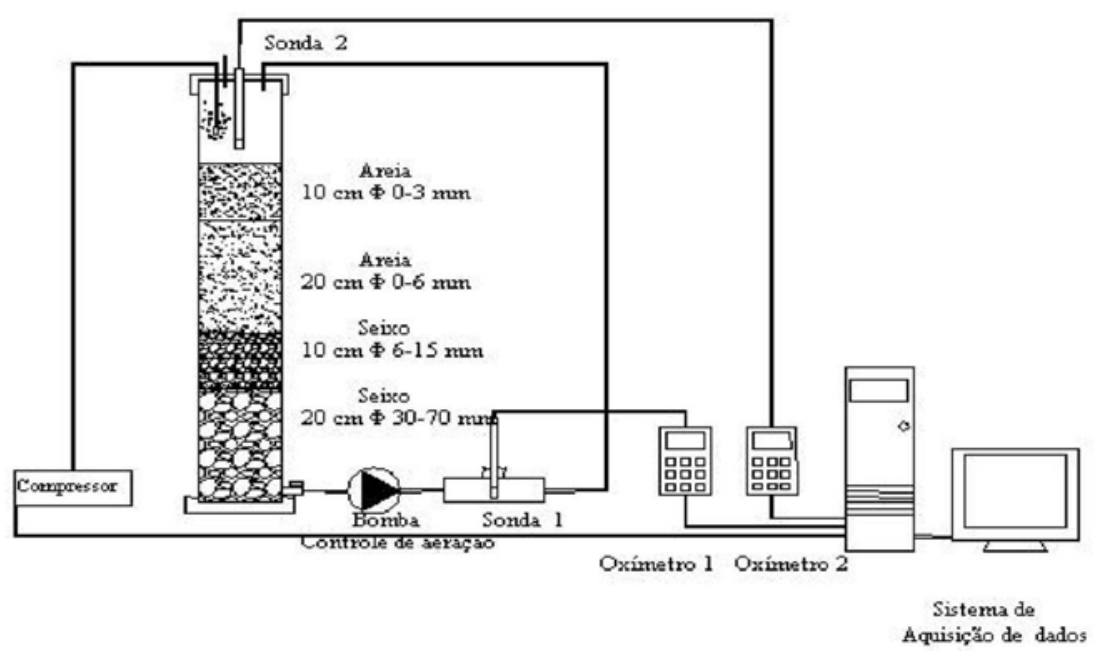

Figura I5 - Esquema do respirômetro desenvolvido para a medição de oxigênio dissolvido em fase aquosa

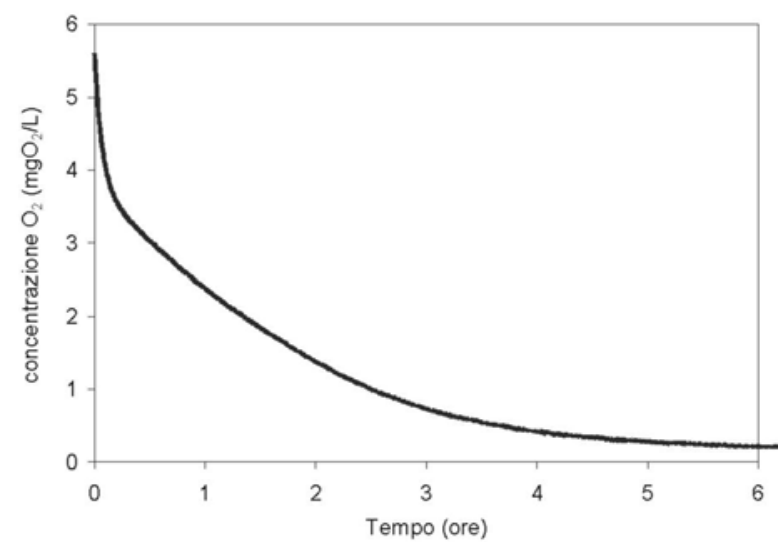

Figura 16 - Exemplo de respirograma obtido através de uma amostra de leito com fluxo vertical submerso, depois da adição da água residuária pré-sedimentada 
$\mathrm{CH}_{4}$ (Giraldo e Zarate, 2001). Devido à possibilidade de desenvolvimento de um biofilme sobre as partículas inertes do terreno, instalam-se condiçôes limitantes com relação à difusão do oxigênio para o interior do mesmo biofilme. Este fenômeno contribui com a formação de zonas anóxicas no estrato mais profundo do biofilme no qual o oxigênio não consegue penetrar.

Os parâmetros cinéticos, a serem obtidos da modelização destes respirogramas, poderão ser utilizados no desenvolvimento de métodos avançados para controle e projetos de sistemas em Alagados Construídos ou terras úmidas ou wetlands (fitodepuração) e para melhorar o balanço de nutrientes e do carbono no efluente final.

\section{AGRADECIMENTOS}

À FAPESP (Fundação de Amparo à Pesquisa do Estado de São Paulo) pela concessão de Bolsa de Pós-Doutorado, ao LISA (Laboratorio di Ingegneria SanitariaAmbientale-) e ao DICA (Dipartimento di Ingegneria Civile e Ambientale) Trento/Itália pela acolhida ao Professor Dr. Eduardo Luiz de Oliveira.

\section{REFERÊNCIAS}

ANDREOTTOLA, G., et al. Respirometria applicata alla depurazione delle acque: principi $e$ metodi. Collana scientifico-divulgativa Monographia, n. 3. Dipartimento di Ingegneria
Civile ed Ambientale, Università degli Studi di Trento. 156p. 2002.

COOPER, P.F., et al. Reed beds and constructed wetlands for wastewater treatment. Medmenham. Marlow, UK: WRc Publications. 1996.

DALLAGO, L. Sviluppo ed applicazione di tecniche respirometriche per valutare la stabilità di matrici solide in fase di compostaggio. Tesi di dottorato in Ingegneria Ambientale, Università degli studi di Trento. 2002.

EKAMA, G. A.; DOLD, P.L. e MARAIS, G.v.R. Procedures for determining influent COD fraction and the maximum specific growth rate of heterotrophy in activated sludge system. Water Science and Technology, 18(6), pp 91-114. 1986.

GIRALDO, E.; ZARATE. Development of a conceptual model for vertical flow wetland metabolism. Water Science and Technology, 44 (11-12), 273-280. 2001.

JENKINS, D. The use of manometric methods in the study of sewage and trade wastes. In: ISSAC, P.C.G. (ed) Wastewater Treatment. Pergamon Press, pp. 99-125. 1960.

KAPPELER, J. e GUJER W. Estimation of kinetic parameters of heterotrophic biomass under aerobic conditions and characterization of wastewater for activated sludege modeling. Water Science and Technology. 25(6), pp 125-139. 1992.

MONTGOMERY, H.A.C. The determination of biochemical oxygen demand by respirometric methods. Wat. Res. 1, pp 631-662. 1967.

$\mathrm{XU}$, S. e HULTMAN, B. Experiences in wastewater characterization and model calibration for the activated sludge process. Water Science and Technology. 33 (12), pp 89-98. 1996.

ZIGLIO, G., et al. Experimental validation of a single-OUR method for wastewater DQORB characterization. Water Science and Technology, 43 (11), 119-126. 2001.

Endereço para correspondência:

Eduardo Luiz de Oliveira

Faculdade de Engenharia - UNESP

Campus de Bauru

Av. Luiz Edmundo Carrijo Coube, S/N

I 7000-360 Bauru - SP - Brasil

Tel: (I 4) 3 I03-6 I I 2 - 3 I03-6 I /3

Fax: (I4) 3103-6I0I

E-mail:eduoliv@feb.unesp.br

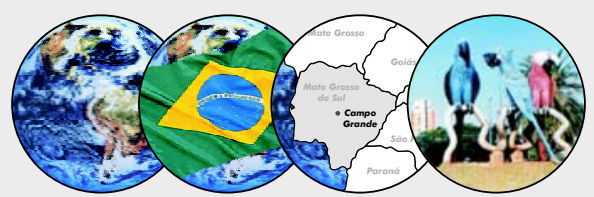

$23^{\circ}$ Congresso Brasileiro de Engenharia Sanitária e Ambiental

\author{
Saneamento Ambiental no Brasil: \\ Utopia ou Realidade?
}

Data: 18 a 23 de setembro de 2005

Local: Centro de Exposições Albano Franco Campo Grande - MS 